\title{
Flipped Classroom as a Teaching Strategy and Community Health Nursing Student's Engagement, Satisfaction and Achievement
}

\author{
Lamia A. Awad ${ }^{1}$, Nadia Ahmed El-Adham ${ }^{2, *}$ \\ ${ }^{1}$ Community Health Nursing, Faculty of Nursing, Mansura University \\ ${ }^{2}$ Community Health Nursing, Faculty of Nursing Fayoum University \\ *Corresponding author: nadia.adham5@gmail.com
}

Received January 17, 2019; Revised March 24, 2019; Accepted April 17, 2019

\begin{abstract}
Flipped Classroom is a promising alternative to traditional lectures in nursing education, helping nursing students become more involved in classroom activities. Can lead to a high level of student satisfaction, self-speed and independence. The aim of this study was to evaluate the effect of inverted education as a teaching strategy on the participation of students in community nursing, satisfaction and achievement. Design: A quasi-experimental design was used in this study (study and control group). Setting: This study was conducted in faculty of nursing at Fayoum University. Subjects: A total number of students 140 students were enrolled in this study, both sex studies at second semester, fourth year during study of community health nursing course, academic year 2016/2017. Tools: data was collected through self-administer questionnaire sheet which include personal characteristics, students engagement scale: satisfaction scale and achievement questionnaire sheet. Results: Around three quartets (71.4\%) of student undergoing flipped classroom as a teaching strategy achieved a moderate level of achievement compared with half (50\%) of student undergoing lecture based learning (post test).There were highly statistical significant between pre and posttest of study and control group regarding student satisfaction and engagement. Recommendations: The need for provided deferent innovative educational strategies for students, introduce Flipped Classroom to other courses for students with different class levels and encourage students for using different models of Flipped Classroom as a teaching strategy.
\end{abstract}

Keywords: flipped classroom, teaching strategy, student, engagement, satisfaction, achievement

Cite This Article: Lamia A. Awad, and Nadia Ahmed El-Adham, "Flipped Classroom as a Teaching Strategy and Community Health Nursing Student's Engagement, Satisfaction and Achievement." American Journal of Nursing Research, vol. 7, no. 3 (2019): 354-359. doi: 10.12691/ajnr-7-3-16.

\section{Introduction}

Education is an enormous manufacturer that needs the effort of both students and teachers. The question as to the most effective method of teaching and learning, however, remains to be seen. Traditional classroom settings consist of an educational method of teaching involving passive learning on the part of the students. This departs a little space for class participation. The environment is created by teachers who are committed to inclusion and value the uniqueness of each student. By participating in this environment, colleagues learn to consider uniqueness as an ordinary aspect of classroom diversity, and students with disabilities acquire a sense of belonging [1,2]. Recently, a new approach of teaching and learning has appeared known as active learning; this dynamic technique commonly operates a team-based approach in order for students to achieve course objectives. The flipped classroom is one form of active learning, which involves student preparation prior to class followed by assessments and application exercises [3].

Traditional way of education is almost teacher-based which conflicts with the constructivist appear to education [4]. The difficulty with traditional lectures in higher education is an issue of rating. With some students, the information provided in the class may be known; differently other students, they may find it difficult to take information as quickly as possible or may lack prior knowledge to realize the concepts offered [5].

New trends in education request encouragement of student centered instruction; Students have a responsibility to learn in a distribution environment, critical thinking, problem solving, a variety of activities, teamwork and significant interactions rather than automatic conservation that leads students to negative education and students are unable to grow and develop [6]. Educators therefore recommended different learning models to beat this drawback. One of these is active learning that involves a combination of face-to-face interaction and online interaction. The goal of blended education is to facilitate increased student learning and promotion [7]. 
There are many benefits of flipped class pass through many phases which include: before class, the students guided through learning model by asking questions and inquiry to prepare important questions, while the teacher prepares learning opportunities. In the beginning of Class, the students have specific questions in mind to guide their learning, while the teacher can expect where students need more help. During Class: Students practice, performing the skills they are expected to learn. While the teacher guides the process with reaction and mini-lectures for interactive discussion. After Class, students continue applying their knowledge and skills after clarifications and reaction. Instructor posts any additional details and resources as necessary and grades of higher quality work. These beside, the responsible faculty staff provided support, explanation and enthusiasm through office hours and tutorial hours [8].

\subsection{Significance of the Study}

The flipped classroom model now being trained in many campuses to foster students learning to analyze, apply, and evaluate conceptions in the classroom from material they have learned and understood outside or previously class [9].

In general, instructors who flipped their ranks reported that higher student achievement, increased student participation and better attitudes toward learning and school. On the other hand, many instructors reported that their job satisfaction has improved and the feeling of reactivation is increased by interaction with students via reverse education. Therefore, this study examined the satisfaction of nursing students in learning overturned and compared their academic achievement between the lecture class and the overturned learning class. This will provide basic data for nursing faculty members to introduce future learning overturned.

\subsection{Aim of the Study}

This study aimed to evaluate the effect of flipped classroom as a teaching strategy on community nursing students engagement, satisfaction and achievement.

Research Hypothesis: the study results were testing the following hypothesis:

- Engagement of community health nursing students group with flipped classroom as a teaching strategy will be better than lecture based learning group.

- Satisfaction of community health nursing students group with flipped classroom as a teaching strategy will be more than lecture based learning group.

- Achievement of community health nursing students group with flipped classroom as a teaching strategy will be better than lecture based learning group.

\section{Research Design}

A quasi - experimental research design was used in this study (study and control group).

\subsection{Study Setting}

The study was conducted in faculty of nursing at Fayoum University.

\subsection{Study Subjects}

A total number of students 140 students were enrolled in this study both sex study at second semester, fourth year during study of community health nursing course, academic year 2016/2017. A number of student were devided randomly as (70) student in the study group (flipped classroom method) and (70) student in control group (lecture based learning method).

To ensure the randomization the odd numbers were received the routine teaching strategy; while the double numbers were received the team based learning strategy during the community nursing course.

\subsection{Data Collection Tool}

Data was collected through self-administer questionnaire sheet which included the following items:

- Personal characteristics: as age, sex, and the place of residence.

- Students Engagement Scale: There are many instruments that measure student engagement $[10,11]$. A number of studies that dealt with engagement were reviewed [12,13]. A 19-item, five-point Likert questionnaire, ranging from (strongly disagree to strongly agree) was designed and distributed to the experimental group to measure student engagement. It was reviewed by a number of experts in language teaching and assessment to examine its validity and some modifications were undertaken. The questionnaire reliability was verified and it was (0.86).

- Satisfaction Scale: To explore student satisfaction with the flipped classroom teaching model (EFL-FCTM), a questionnaire was designed for this purpose depending on the previous research on satisfaction [14]. The questionnaire contained 16-five-point Likert items, ranging from (strongly disagree to strongly agree).It was reviewed by a number of experts in language teaching and assessment to examine its validity and some modifications were carried out. The questionnaire reliability was examined using Cronbach's Alpha (0.81). It was administered to the experimental group students only after the intervention.

- Achievement questionnaire sheet: It was developed and utilized by the researcher based on an extensive literature review to assess students' level of knowledge regarding four lectures at community health nursing. It included multiple choice, essay and matching questions.

- Scoring system for this part: each correct answer scored 1 mark, each wrong one scored zero and graded into: high level of achievement $\geq 80 \%$, moderate level of achievement $75<80$, low level of achievement $60<75$. 


\subsection{Pre-testing Validity}

- A jury of three staff member from faculty of nursing examined the tools and approved their face validity and suitability to the level of subjects and to the set objectives. Statistically computed validity of the three tools was obtained from the square root of the reliability score of the two. A validity coefficient was (85\%).

\subsection{Reliability}

- A pilot testing for 3 tools was performed on 10\% (6 students) of the sample at the beginning of the academic term 2017-2018. The test - retest method with two weeks interval was used to calculate reliability coefficient of the tools. The reliability coefficient was (0.72)

\subsection{Ethical Considerations}

- $\quad$ Each subject of the study was ensured that the study was not harmful either physical or psychological and treated all data collected secretly, and was used for research purposes only. The researcher took verbal approval from each student before participating in the study.

\subsection{Pilot Study}

- Pilot study was conducted on 7 (10 \%) of students and they were excluded from the total number of students to insure the clarity and comprehensiveness of the tool.

\subsection{Field Work}

- An official agreement was obtained from the Dean of the Faculty of Nursing, at Fayoum University to collect the necessary data at academic year 2017-2018, first term. The study last 3 month from beginning of academic year.

- An orientation guide was developed by the researchers and distributed to the students one week before the course to prepare the students for using cooperative learning approach.

- The teacher first explained what is cooperative or team based learning and its five main principles to the students (experimental group).

- Second the teacher divided the 30 students in the experimental group into 5 groups, each group consisted of 6 students. Dividing the students depended on their academic level, the researcher made uses of the scores of questionnaire sheet of pretest as bases score.

- Sub-topics were selected to make up a lesson which is one of the main objectives four lectures at community health nursing was chosen .The total number of lectures in community health nursing course is 16 lectures from this number the researchers selected four lectures from the total number (16) which represented 25\% from the course of community health nursing. The instructors selected name: occupational health nursing, environmental health, common health problems in Egypt and disaster nursing management. The teachers begin to verify the learning outcomes of the lectures.

- The videos were distributed to students before the initiation of the clinical rotation either by sending through email or social media (Facebook) or CDs of videos were given to them for those who did not have not any access to internet.

- Students were asked to view those videos before attending their clinical course.

- Subjected to study on a group basis in their ranks and asked them to participate in the study as the implementation of a new strategy of education.

- Class activities are designed with sufficient time to apply knowledge and skills in class based on the objectives of the subject.

- Each group was grouped into 6 subgroups and case studies were distributed to each group and each subgroup was tried to solve problems based on what it had previously seen.

- Each group is encouraged to work collaboratively to solve the relevant practice problems. These courses usually take 60-90 minutes.

- Each group presented their case study, as a result of appropriate management.

- After the clinical course, students are asked to fill out a questionnaire about their satisfaction with the teaching method such as the use of videos that were part of the reflection - teaching approach, experiences and strategic perceptions turned over the classroom.

- At the end of the lesson, students have to do projects, presentations and assignments related to the lesson. These activities are evaluated by the instructor to ensure that learning outcomes are achieved. Finally, each step of the model is evaluated to give feedback to the entire lesson. The teacher has been distributed the evaluation paper to assess student survey, student participation, reverse learning satisfaction and achievement.

\section{Statistical Analysis}

The collected data were organized, tabulated and statistically analyzed using SPSS software statistical computer package version 19.0. Data summarized using mean and standard deviation for numerical variables. Also paired $\mathrm{t}$ test was used to test the difference between pre and post scores of both: achievement questionnaire sheet and students' satisfaction with learning methods. The level of significance selected for this study was $\mathrm{p}<0.05$ level.

\section{Results}

Figure 1: This figure represent that the majority of study sample were female, single and from rural area.

Table 1 show that there were highly statistical significant between pre and posttest of study and control group regarding student satisfaction and engagement. 
Figure 2: Reveals that around three quartets (71.4\%) of student undergoing flipped classroom as a teaching strategy achieved a moderate level of achievement compared with half (50\%) of student undergoing lecture based learning (post test).

Table 2: This table shows that positive correlation between satisfaction and engagement among flipped classroom post test.

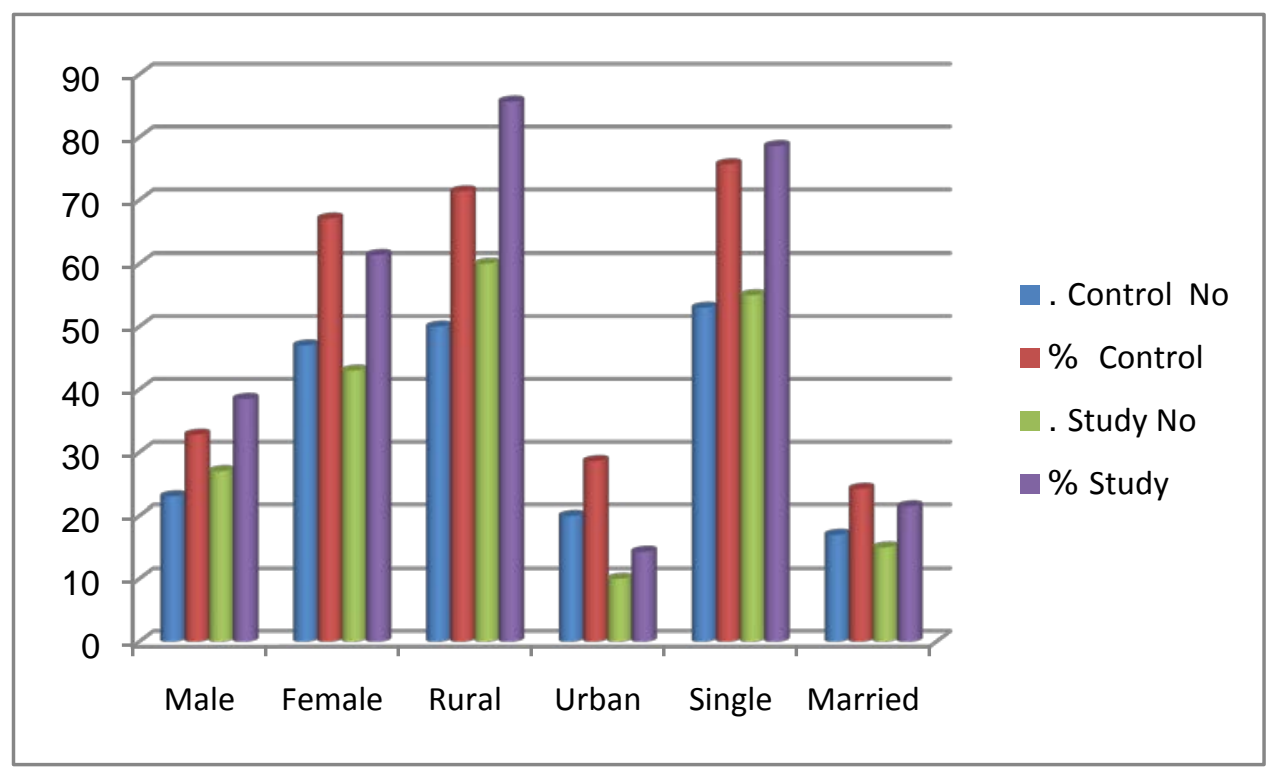

Figure 1. Distribution of student's characteristics in the study and control group (No (140))

Table 1. Comparison between total scoring of satisfaction and engagement among study and control group pre and posttest n=140

\begin{tabular}{|c|c|c|c|c|c|c|}
\hline \multirow{3}{*}{ Variables } & \multicolumn{2}{|c|}{ Pretest } & \multicolumn{2}{|c|}{ Posttest } & \multirow{3}{*}{ P1.v } & \multirow{3}{*}{ p.v } \\
\hline & \multicolumn{2}{|c|}{ Mean \pm Sd } & \multicolumn{2}{|c|}{ Mean \pm Sd } & & \\
\hline & Control & Study & Control & Study & & \\
\hline Total student satisfactions & $24.0000 \pm 3.476$ & $24.34 \pm 3.926$ & $70.028 \pm 7.438$ & $74.17 \pm 3.647$ & $.585 n s$ & $.001^{*}$ \\
\hline Total student engagement & $27.32 \pm 4.986$ & $27.28 \pm 5.045$ & $80.514 \pm 7.166$ & $86.10 \pm 5.253$ & $.960 \mathrm{~ns}$ & $0.001^{* *}$ \\
\hline
\end{tabular}

Independent t-test, $*=$ Significant difference $* \mathrm{p} \leq 0.05, * *=$ highly significance $* \mathrm{p} \leq 0.01$, =Ns Significant difference $\mathrm{p}$

$>0.05$

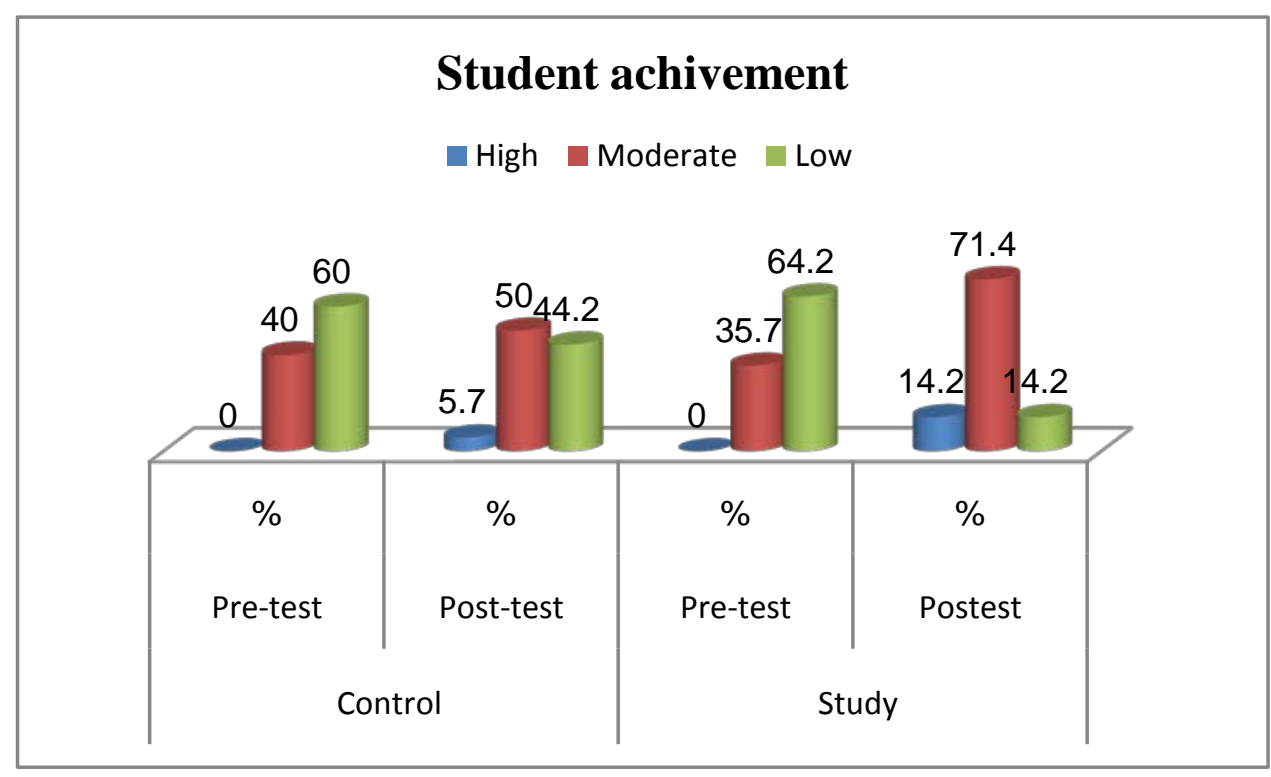

Table 2. Correlation between satisfaction and engagement of flipped classroom group pre and post test

\begin{tabular}{|c|c|c|c|}
\hline \multirow{2}{*}{ Variables } & & \multicolumn{2}{|c|}{ Engagement } \\
\cline { 3 - 4 } & & Pearson correlation & Sig.p.v \\
\hline \multirow{2}{*}{ Satisfaction } & Pre-test & .056 & .512 \\
\cline { 2 - 4 } & Post -test & $.433^{* *}$ & .001 \\
\hline
\end{tabular}

** Correlation is significant at the 0.01 level (2-tailed). 


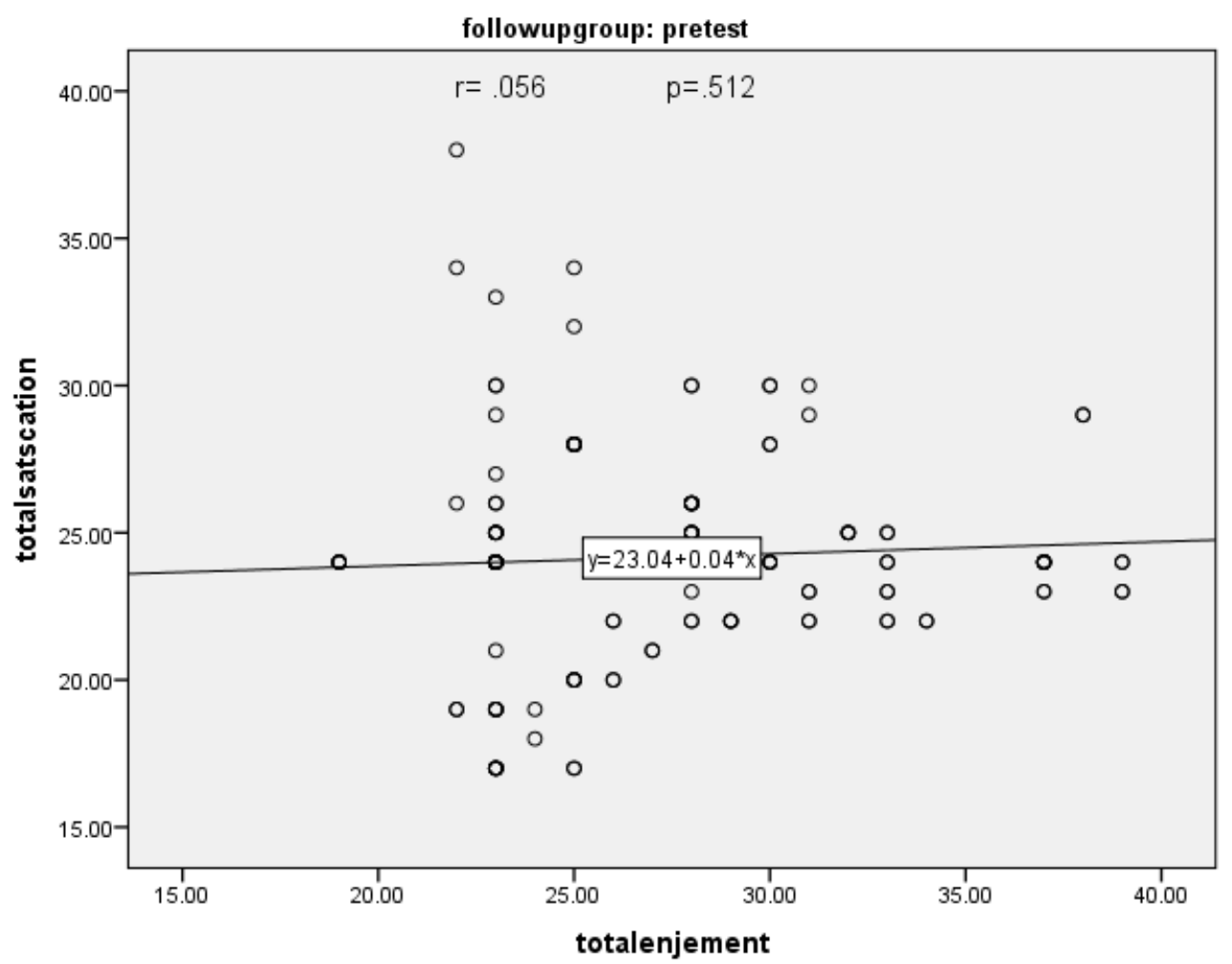

Figure 3. This figure shows that positive correlation between satisfaction and engagement among flipped classroom post tes

\section{Discussion}

In the typical classroom, students attend regular class lectures and then do exercise at home. While, reverse instruction allows students to read articles and watch videos at home and then work with their peers on projects during school hours. All of these skills increase teamwork, enhance mutual understanding and trust $[15,16]$.

The current study was conducted to assess the impact of overturned classrooms and engage the education strategy and community health student nursing, satisfaction and achievement during community health nursing. With regard to the characteristics of the study sample, the study showed that the majority of the study sample is female, one is rural.

The results of the current study revealed that about three quarters of the student pass-through many overturned the classroom and achieved a teaching strategy at a moderate level of achievement on the course of community health nursing courses compared to students undergoing a learning-based lecture (after the test).

The increase in quality and academic achievement is one of the main objectives of education and teachers can play an important and effective role in the academic achievement of students by choosing appropriate methods [17]. On the other hand, [18] mentioned that Collaborative learning only improves students' achievement when their teacher puts them in small groups and provides a clear goal for them, and this improvement is achieved when all group members master the learning content. In other words, if there is a possibility that one or more group members finds an answer and shares with others, or performs the intellectual part of a set assignment while others only observe, then in this case, collaborative learning is not achieved.

Our study explored that positive correlation between satisfaction and engagement among flipped classroom post test. This was inconsistent with $[9,19]$ who found that overall higher level of course satisfaction benefit were amongst students who had experienced the Flipped Classroom pedagogical model Students. Furthermore, Jerri, et al. [20] mentioned that ,students reported that they had the ability to present lectures in video format, repetitive parts of videos that were not clear on the first monitor, flexibility and the ability to re-listen to lectures. They also stated that FC helped students to become an independent learner and to promote ideas and interest. In addition in some studies by [21,22], a strong relationship between students' satisfaction and academic performance was found indicating that groups with higher academic achievement had higher satisfaction than groups with low academic achievement . On the contrary, [23] did not find a correlation between students' satisfaction and performance, whereas study satisfaction was determined by "noncognitive" factors such as motivation and course organization, while academic performance was influenced by "cognitive" factors such as final school grade and students' learning behavior. Although there is some evidence that psychological characteristics such as personality traits and emotional intelligence can also contribute to both academic success and student satisfaction, the results are inconsistent. Also, [22] their study founded that there were strong relationship between satisfaction of students and academic performance as pearson correlation displayed in table one. The study also found that satisfaction promotes both academic achievement and student retention.

\section{Conclusions and Recommendations}

There was a positive effect of using Flipped Classroom as a teaching strategy and community health nursing 
student's engagement, satisfaction and achievement during the course of community health nursing. In the light of previous findings we can recommended that the need for provide deferent innovative educational strategies for students. Introduce Flipped Classroom to other courses for students with different class levels and encourage students for using different models of Flipped Classroom as a teaching strategy.

\section{Acknowledgments}

The authors are indebted to all community health nursing students, enrolled at the fourth year at the Faculty of Nursing, Fayoum University who agreed to participate in this study for their cooperation and participation in this study.

\section{References}

[1] Alberta E.. (2013). Indicators of inclusive schools: Continuing the Conversation. Recuperado de

https://education.alberta.ca/media/6880391/indicators_of_inclusiv e_schools. Pdf

[2] Zitomer, M. R. (2016). Creating Inclusive Elementary School Dance Education Environments.'

[3] Velegol, S. B., Zappe, S. E., \& Mahoney, E. M. I. L. Y. (2015) The Evolution of a Flipped Classroom: Evidence-Based Recommendations. Advances in Engineering Education, 4(3), n3.

[4] Punja, D., Kalludi, S. N., Pai, K. M., Rao, R. K., \& Dhar, M. (2014). Team-based learning as a teaching strategy for first-year medical students. The Australasian medical journal, 7(12), 490.

[5] Goodwin, B., \& Miller, K. (2013). Evidence on flipped classrooms is still coming in. Educational Leadership, 70(6), 78-80.

[6] Brown, J. K. (2008). Student-centered instruction: Involving students in their own education. Music Educators Journal, 94(5), 30-35.

[7] McLaughlin, J. E., White, P. J., Khanova, J., \& Yuriev, E. (2016). Flipped classroom implementation: a case report of two higher education institutions in the United States and Australia. Computers in the Schools, 33(1), 24-37.

[8] Shi-Chun, D., Ze-Tian, F., \& Yi, W. (2014, April). The flipped classroom-advantages and challenges. In 2014 International Conference on Economic Management and Trade Cooperation (EMTC 2014). Atlantis Press.

[9] Farah, M. (2014). The Impact of Using a Flipped Classroom Instruction on the Writing Performance of Twelfth Grade Female
Emirati Students in the Applied Technology High School (ATHS). Master thesis. The British University, Dubai.

[10] Gunuc, S. \& Kuzu, A. (2015). Student engagement scale: development, reliability and validity. Assessment \& Evaluation in Higher Education, 40(4), 587-610.

[11] Uğur, E. \& Akın, A. (2015). The Psychometric Properties of Turkish Version of the Student Engagement Scale. International Journal of Educational Studies, 2(1), 53-59.

[12] Shermila, J. (2015). Teaching Poetry through Classroom Flipping among Prospective Teachers in a College of Education - Action Research Report. International Journal of English Language, Literature and Humanities, 3(10), 423-430.

[13] Johnson, G. (2013). Student Perceptions of the Flipped Classroom. Master Thesis. The University of British Columbia, Okanagan.

[14] Hung, H. (2015). Flipping the classroom for English language learners to foster active learning. Computer Assisted Language Learning, 28(1), 81-96.

[15] Sarah Zappe, Robert Lieicht, John Messner, Thomas Litzinger, and Hyeon Woo Lee. (2009). "Flipping" the classroom to explore active learning in a large undergraduate course. In Proceedings, American Society for Engineering Education Annual Conference \& Exposition, 2009.

[16] Bishop, J. L., \& Verleger, M. A. (2013, June). The flipped classroom: A survey of the research. In ASEE national conference proceedings, Atlanta, GA (Vol. 30, No. 9, pp. 1-18).

[17] Ghaffari, R., Ranjbarzadeh, F. S., Azar, E. F., Hassanzadeh, S. Safaei, N., Golanbar, P., ... \& Abbasi, E. (2013). The analysis of learning styles and their relationship to academic achievement in medical students of basic sciences program. Research and Development in Medical Education, 2(2), 73.

[18] Slavin, R. E. (2004). When and why does cooperative learning increase achievement. The RoutledgeFalmer reader in psychology of education, 1, 271-293.

[19] Moraros J, Islam A, Yu S, Banow R, and Schindelka B. (2015): Flipping for success: evaluating the effectiveness of a novel teaching approach in a graduate level setting. BMC Med Edu., 28 (15) 27.

[20] Jerri L., Deal B, Hermanns M. (2015). Implementation of a Flipped Classroom: Nursing students' perspective. Journal of Nursing Education and Practice, 5(6). 25-30.

[21] Thompson, C. (2013). Emotional intelligence and graduate student satisfaction at online institutions of higher education. (Unpublished Doctoral Dissertation). Walden University, Minneapolis.

[22] Dhaqane, M. K., \& Afrah, N. A. (2016). Satisfaction of Students and Academic Performance in Benadir University . Journal of Education and Practice, 7(24), 59-63.

[23] Blanz, M. (2014). How do study satisfaction and academic performance interrelate? An investigation with students of Social Work programs. European Journal of Social Work, 17(2), 281-292.

[24] Chi, U. (2014). Classroom Engagement as a Proximal Lever for Student Success in Higher Education: What a Self-determination Framework within a Multi-Level Developmental System Tells Us. Doctoral Thesis, Portland State University. 